\title{
Lighting-Up the Dynamics of Telomerization and DNA Replication by CdSe-ZnS Quantum Dots
}

\author{
Fernando Patolsky, Ron Gill, Yossi Weizmann, Taleb Mokari, Uri Banin \\ and Itamar Willner* \\ Institute of Chemistry and the Farkas Center for Light Induced Processes The Hebrew University of \\ Jerusalem Jerusalem 91904, Israel
}

\section{Supporting Information}

1. Synthesis of water soluble CdSe-ZnS nanoparticles: Trioctylphosphine oxide (TOPO) protected particles (77\% luminescence quantum yield), soluble in organic solvents were reacted in toluene $(1 \mathrm{ml})$ with $100 \mu$ of mercaptopropionic acid overnight. (Protected from light with aluminum foil). After this incubation time the particles were transfered to water by adding $1 \mathrm{M} \mathrm{KOH}$ solution $(1 \mathrm{ml})$, the two phase mixture was separated and the process was repeated a second time with clean toluene $(1 \mathrm{ml})$. The water-soluble CdSe-ZnS nano-particles were separated from the excess of mercaptopropionic acid by 3 repeated cycles of precipitation of the particles with acetone, followed by the re-dissolution of the particles in a phosphate buffer solution $\mathrm{pH}$ $7.4,10 \mathrm{mM}$.

2. Preparation of DNA-modified CdSe-ZnS nanoparticles: The mercaptopropionic acid functionlized CdSe-ZnS particles (0.1 O.D) were reacted with freshly reduced and purified thiolated oligonucleotides ((1) or (3)) 6-10 O.D) overnight in order to allow the the exchange of the thiol group associated with the particles with the thiolated oligonucleotide. The DNA modified particles were separated from the free oligonucleotides by the use of a micro-spin filter (Millipore, 30KDa) or by acetone precipitation and re-dissolution in phosphate buffer solution. The nucleic acid-modified particles were obtained with a $70 \%$ yield. The fluorescence quantum yield of the nucleic acid-functionalized nanoparticles is ca. 22\%. The particles are stable for at least 6 weeks in buffer solution $\left(25^{\circ} \mathrm{C}\right)$.

\section{Determination of the loading of the CdSe-ZnS QDs with the oligonucleotides (1)}

and (3): The absorption spectrum of the CdSe- $\mathrm{ZnS}$ nanoparticles of known concentration (ca. 0.1 O.D. at $450 \mathrm{~nm}$ ) is recorded prior to the modification of the particles. The absorption spectrum of the oligonucleotide-functionalized CdSe-ZnS QDs is then 
recorded and the spectrum is normalized to the same O.D. value at $450 \mathrm{~nm}$ observed for the non-modified QDs. Since DNA is not absorbing at 450nm, the substraction of the spectrum of the oligonucleotide-functionalized QDs from the non-modified QDs yields the absorbance of the associated DNA. The absorbance difference at $\lambda=260 \mathrm{~nm}$ allows the calculation of the concentration of DNA. Knowing the concentration of QDs, the QDs/DNA ratio is then calculated.

4. The analysis of M13- DNA by FRET: 0.1 O.D of DNA (3)-modified CdSe-ZnS nanoparticles were incubated in a solution containing a mixture of dATP, dCTP, dGTP $(0.5 \mathrm{mM}$ each) and Texas-Red 14-dUTP $(100 \mu \mathrm{M})$ in the presence of M13 $\phi$ DNA, $1 \mathrm{nM}$ concentration, at $25^{\circ} \mathrm{C}$. The luminescence of the sample was followed in a quartz cuvette at different time intervals of replication $\lambda_{\text {exitation }}=400 \mathrm{~nm}$.

5. The following control experiments confirm that the fluorophore light emission originates from a FRET process to the dye labels that were incorporated into the DNA replica:

(a) Treatment of the (3)-functionalized CdSe-ZnS QDs with TR-dUTP, (2), or with TR-dUTP and polymerase, does not lead to any time-dependent increase in the fluorescence of the dye.

These experiments indicate that the observed light emission does not originate from non-specific binding of (2) to the particles.

(b) The replication of the hybridized M13 $\phi$ DNA with the (3)-functionalized QDs in the presence of polymerase (klenow fragment), the dNTPs and unlabeled dUTP does not lead to the quenching of the QDs fluorescence.

(c) Excitation of the dNTP mixture that includes (2) in the absence of the (3)functionalized QDs, at $\lambda=400 \mathrm{~nm}$, does not lead to an emission at $\lambda=560 \mathrm{~nm}$. Excitation of the system at $\lambda=560 \mathrm{~nm}$ yield a high fluorescence of the dye.

6. The analysis of Telomerase activity by FRET: 0.1 O.D of the (1)-modified $\mathrm{CdSe}-\mathrm{ZnS}$ nanoparticles was incubated in a solution containing a mixture of dATP, dCTP, dGTP $(0.5 \mathrm{mM}$ each) and Texas-Red 14-dUTP $(100 \mu \mathrm{M})$ in the presence of telomerase, (cell extracts containing telomerase in $1 \mathrm{xChaps}$ buffer), at $25^{\circ} \mathrm{C}$. The luminescence of the sample was followed in a quartz cuvette at different time intervals of replication $\lambda_{\text {exitation }}=400 \mathrm{~nm}$. 
7. Imaging the telomerization on the CdSe-ZnS nanoparticles by AFM: The sample for the AFM imaging of the QDs-telomer assembly was prepared by filtration of the telomerized QDs mixture through a Centricon filtration device (30,000 MW), followed by the addition of acetone to the residue (10\%) and centrifugation (5,000 r.p.m.). The precipitated QDs where re-solubilized in water for subsequent deposition on the mica surfaces. Freshly-cleaved Ruby-mica surfaces were used (activated with $5 \mathrm{mM} \mathrm{MgCl}$ ). A drop of nano-particles solution (before or after telomerization) was placed on the mica surface and after evaporation the surface was wash with $2 \times 100 \mu l$ water, dried under a gentle flow of argon and the AFM were recorded. 